\title{
Diverse Role of Silicon Carbide in the Domain of Nanomaterials
}

\author{
T. Sahu, ${ }^{1}$ B. Ghosh, ${ }^{1}$ S. K. Pradhan, ${ }^{2}$ and T. Ganguly ${ }^{3}$ \\ ${ }^{1}$ Department of Physics, Ramananda College, Bishnupur, West Bengal, Bankura 713104, India \\ ${ }^{2}$ Department of Physics, The University of Burdwan, Golapbag, West Bengal, Burdwan 722122, India \\ ${ }^{3}$ Department of Spectroscopy, Indian Association for the Cultivation of Science, Jadavpur, Kolkata 700032, India
}

Correspondence should be addressed to T. Ganguly, tapcla@rediffmail.com

Received 16 February 2012; Accepted 9 June 2012

Academic Editor: Ujjal Kumar Sur

Copyright () 2012 T. Sahu et al. This is an open access article distributed under the Creative Commons Attribution License, which permits unrestricted use, distribution, and reproduction in any medium, provided the original work is properly cited.

\begin{abstract}
Silicon carbide $(\mathrm{SiC})$ is a promising material due to its unique property to adopt different crystalline polytypes which monitor the band gap and the electronic and optical properties. Despite being an indirect band gap semiconductor, SiC is used in several highperformance electronic and optical devices. SiC has been long recognized as one of the best biocompatible materials, especially in cardiovascular and blood-contacting implants and biomedical devices. In this paper, diverse role of SiC in its nanostructured form has been discussed. It is felt that further experimental and theoretical work would help to better understanding of the various properties of these nanostructures in order to realize their full potentials.
\end{abstract}

\section{Introduction}

In present times group IV semiconductors, in general, are not as popular as they were before in the field of optics and optoelectronics. The reason lies in their indirect bandgaps, which make their luminescence efficiency very low at room temperature. In optoelectronics, devices made of group III/V composites such as GaAs dominate at the present time.

1.1. Superiority of Silicon Carbide over Silicon and Carbon. Carbon is the backbone of all known life forms on earth. In the human body, it is the second most abundant element by mass after oxygen. Carbon in nature exists mostly in the form of graphite, diamond, and amorphous carbon. Silicon is the basic material used in integrated circuits and the principal component of semiconductor devices. Silicon is also an essential element to sustain life. The compound of silicon and carbon, silicon carbide ( $\mathrm{SiC}$ ), a semiconductor with superior characteristics, is widely used in high-temperature, highpower, and high-frequency electronic applications. It is also one of the best biocompatible materials.

1.2. What Is So Fascinating about Silicon Carbide? Bulk silicon carbide is a wide band gap IV-IV semiconductor with interesting and well-known physical properties. The band gap of $\mathrm{Si}$ at room temperature is $1.12 \mathrm{eV}$ whereas diverse for $\mathrm{SiC}$ because it exists in over 200 crystalline forms and among them the most common types are $3 \mathrm{C}, 6 \mathrm{H}$, and $4 \mathrm{H}$, which have band gaps of 2.2, 3.02, and $3.20 \mathrm{eV}$, respectively [1]. Silicon carbide is a promising material due to its unique ability to adopt different crystalline polytypes which monitor the band gap and then the electronic and optical properties [2-4]. Despite being an indirect band gap semiconductor, $\mathrm{SiC}$ is used in several high-performance electronic and optical devices due to its unique physical and electronic properties. High chemical stability facilitates $\mathrm{SiC}$ applications in hostile environments. Also, Silicon carbide has been long recognized as one of the best biocompatible materials [5], especially in cardiovascular and blood-contacting implants and biomedical devices.

1.3. Suitability of SiC in Fluorescence: An Important Tool in Biological Research. Fluorescence is a detection method used in all aspects of biological research: bioanalytical assays, cell imaging, biosensors, and in vivo cell targeting. Thus, advances in biology and medicine strongly depend on the performances of fluorescence measurements. In particular, for cell imaging, efficient fluorescent nanoprobes are needed to detect very weak concentration of cancer cells in order to make early diagnoses. Combined to high-fluorescence 
properties, an efficient nanoprobe must also be photostable, monochromatic, and weakly toxic. Semiconducting nanoparticles based on $\mathrm{SiC}$ were recently used successfully for the fluorescent imaging of living cells [6]. Known for its chemical and thermal stability, SiC is suitable for this application.

\subsection{Quantum Dots: More Advantageous Substitute for Organic} Fluorophores. Interest in semiconducting nanocrystals, or quantum dots (QDs), is growing because of their unusual physical properties, reported for particles that are less than few nanometers in diameter [7]. Photoluminescent QDs are increasingly being used as biological tags and are becoming an alternative to traditional organic dye based fluorophores [8]. Their main advantages over organic fluorophores are superior stability against photobleaching and size-tunable emission wavelength.

\subsection{Reason Why Group IV Nanostructures Dominate in Mod-} ern Era. With the advent of nanoscience and nanotechnology, there has been increasing interest in obtaining efficient luminescence from group IV nanostructures for two reasons. First of all, extensive investigations have demonstrated that the fluorescence efficiency in group IV nanostructures can be improved by several orders of magnitude with respect to that of bulk materials. Their quantum yield can be closer to or even higher than those of some bulk or nanostructured direct band gap semiconductors. This results from substantially enhanced radiative recombination rates and suppressed or relatively reduced nonradiative recombination rates due to spatial confinement in the nanostructures [9]. Secondly, group IV nanoparticles are more benign to human beings and environments compared with semiconductor nanocrystals that contain cytotoxic heavy metal atoms. Thirdly, fluorescent semiconductor (including group IV) nanocrystals, also known as quantum dots, have demonstrated their great potential in biological imaging and diagnostics as they have such virtues superior to traditional organic dyes as high resistance against photobleaching, composition/size-dependent absorption, and emission, as well as broad absorption spectra and narrow emission spectra (for monodisperse nanoparticles) $[10,11]$. Hence, they are suitable for long-term and multicolor labeling in the monitoring of intracellular processes [12-14]. Furthermore, they can serve as drug delivery platforms in therapeutics. In this respect, group IV nanoparticles bring new hopes as benign materials accompanied by the above-mentioned properties, which favor their biological applications.

Another advantage of group IV nanostructures is that they can be readily made water-soluble as-prepared or via subsequent surface functionalization; this is a necessary condition for applications in a physiological environment. Also, all the group IV materials can form chemical bonds with various types of ligands especially biomolecules [15].

According to the quantum confinement effect, as the size of a semiconductor particle diminishes to be near or smaller than its bulk exciton Bohr diameter, the corresponding energy gap will increase with decreasing size, and accordingly its fluorescence arising from interband transitions of carriers (electrons and holes) will shift to blue [16]. As a result, the emissions in group IV nanoparticles with different sizes will span the whole spectral region from near-IR to visible to near-UV. This virtue is favourable for their applications in biological imaging and sensing.

1.6. Silicon Carbide Nanostructures versus Silicon Nanomaterials. The physical properties of functional hybrid nanocomposites were intensively investigated during the last decade. Among the reported functionalities, those in optics [17], electronics [18], photovoltaic [19], or optoelectronics [20] are very promising. As far as the functionalities are concerned, the active vectors consist in inorganic semiconducting nanocrystals.

Silicon nanoparticles, despite being comprised of an indirect band gap material, can exhibit photoluminescence at visible wavelengths, an effect attributed to quantum confinement [21]. Unlike their direct band gap counterparts, silicon nanomaterials are bioinert [22] but their wider acceptance as alternative fluorophores is presently limited by poor emission stability in aqueous environments [23]. Nanostructured silicon carbide has unique properties that make it useful in microelectronics, optoelectronics, and biomedical engineering and have thus attracted much interest from the materials and device communities. In the microelectronics industry, silicon carbide is regarded as a promising substitute for silicon, especially in high-power, high-temperature, and highfrequency devices $[24,25]$. This wide bandgap biocompatible [26] material was recently shown to exhibit blue/yellow photoluminescence in nanoscale structures [27]. The SiC nanoparticles are characterized by versatile properties such as dielectric behavior marked by interfacial polarizations [2830 ] as well as the vibrational and luminescence properties which point out the main role of surface nature $[3,4]$.

The luminescent properties of $\mathrm{SiC}$ nanocrystals have been observed to be quite variable and strongly depend on the fabrication methods and even on the specific measurements. The emission band can span a wide spectral range from 400 to $500 \mathrm{~nm}$. No luminescence exhibiting obvious quantum confinement has been reported until recently. This is in contrast to porous $\mathrm{Si}[21,31]$ and $\mathrm{Si}$ nanocrystals [32-35] from which quantum confinement can be more easily observed. As a binary compound, silicon carbide has complex surface states and structures [36-39]. The main reasons why quantum confinement is not easily achieved in $\mathrm{SiC}$ are that there are many surface or defect states which dominate the luminescence and that the $\mathrm{SiC}$ nanocrystals are too large [40].

On the theoretical front, the results of investigations on the structure and electronic properties of $\mathrm{SiC}$ nanostructures, employing semiempirical and first-principle calculations [41-43] suggest that the band gap of $\mathrm{SiC}$ nanostructures has a strong dependence on their sizes and surface compositions.

1.7. Charisma of Different Varieties of SiC Nanostructures. Among the different kinds of $\mathrm{SiC}$ nanostructures, SiC nanocrystals which have potential applications as nanoscale 
light emitters were the first to receive attention and have been studied extensively in the last fifteen years. Optically, bulk $\mathrm{SiC}$ shows weak emission at room temperature on account of its indirect band gap [44]. However, the emission intensity can be significantly enhanced when the crystallite size diminishes to several or tens of nanometers [21, 45]. This is thought to be caused by depressed nonradiative recombination in the confined clusters [33]. In accordance with the quantum confinement (QC) effect, photoluminescence (PL) of the crystallites with diameters below the Bohr radius of bulk excitons is shifted to blue with decreasing sizes $[46,47]$. Consequently, wavelength-tunable emissions can be achieved by preparing crystallites with different sizes. The large band gap of $\mathrm{SiC}(2.23 \mathrm{eV}$ for $3 \mathrm{C}-\mathrm{SiC})$ renders the nanocrystals a good candidate as blue and ultraviolet (UV) light emitters in displays. This is in contrast to silicon crystallites from which strong and stable emissions in these spectral ranges are difficult to achieve [45]. Moreover, the high chemical and thermal stabilities [48] of silicon carbide make the luminescence from these nanocrystals very stable enabling the use of the materials in harsh environments and demanding applications. Combined with their excellent biocompatibility, especially blood compatibility, low density, and high rigidity [1,49], SiC nanocrystals are potentially useful in biology and medicine as well, for example, in biolabelling $[7,50]$.

Recently, one-dimensional (1D) $\mathrm{SiC}$ nanostructures such as nanowires [51] and nanotubes [52] have attracted a lot of interests because they play a crucial role as the building blocks in molecular electronics [53]. Silicon carbide nanowires that have outstanding mechanical property and high electrical conductance can be used to reinforce composite materials or as nanocontacts in a harsh environment. Moreover, the materials have good field electron emission properties and biocompatibility.

The optical and electrical properties of nanometersized silicon carbide structures are particularly crucial to efficient and stable SiC nanodevices. SiC nanowires have been shown to have stable field electron emission properties $[54,55]$, suggesting that the materials have potential as field electron emitters. The heterostructures of single-walled carbon nanotubes and silicon carbide nanorods [56] may play an important role in future hybrid nanodevices. The intense, robust, and wavelength-tuneable visible emission from 3C-SiC nanocrystals shows that they are good light sources [27] applicable to nanooptoelectronic integration. Nanocrystalline SiC films which emit visible light [57] are also promising in large area displays. Furthermore, silicon carbide is a biocompatible material [58] and biosensors made of these materials may be realized in the future. Considering the chemical stability and water-solubility, luminescent silicon carbide nanocrystals may find applications in biotechnology/medicine [59].

Bulk silicon carbide is a wide band gap IV-IV semiconductor with interesting and well-known physical properties. Nanoscale engineering of this material allows considerable extension of its basic physicochemical properties. For example, $\mathrm{SiC}$ nanostructures have shown greater elasticity and strength than bulk $\mathrm{SiC}[60]$, and $\mathrm{SiC}$ nanowires have an electron field emission threshold comparable to that of a carbon nanotube-based material as well as stable emission properties [55]. Niu and wang [61] recently reported an application of SiC nanowires covered with platinum as an efficient electrocatalyst for hydrogen adsorption/desorption and methanol oxidation. Various $\mathrm{SiC}$ nanostructures such as nanospheres, nanowires, nanorods, nanopowders, and even nanoflowers have been developed $[51,56,62-66]$. Special efforts of the researchers were oriented to grow $\mathrm{SiC}$ nanoparticles on Si substrates [67, 68]. Incorporation of SiC nanostructures into polymer matrices to form new kinds of composite materials was also carried out and studied [69]. For example, a linear electro-optic effect in polymer matrices containing SiC nanocrystallites was experimentally observed and reported [70].

\section{Mechanical Alloying: A Superior Fabrication Technique}

Usually, metal carbides are prepared by conventional powder metallurgy route, liquid phase sintering technique [71, 72], solid vapor reaction process [73], or chemical vapor reaction [74] which requires a very high temperature as well as good vacuum condition or ultra-pure inert gas atmosphere. One "top down" physical method for preparing homogeneous nanocrystalline metal carbides is mechanical alloying (MA) [75-85]. MA has the advantages over other fabrications techniques as the final product takes a nanocrystalline structure with superior properties in comparison to conventional coarse grained materials. Enayati et al. and Abderrazak and Abdellaoui reported that nanocrystalline $\mathrm{SiC}$ can be prepared using MA $[79,85]$ with a very high ball-to-powder mass ratio (BPMR 67:1). Amorphisation of Si during mechanosynthesis of $\mathrm{SiC}$ has been reported by several authors $[86,87]$.

\subsection{Phenomena Associated with Mechanical Alloying. Heavy} plastic deformation such as MA introduces a high density of lattice imperfections in prepared materials, which are responsible for the observed peak broadening of their X-ray diffraction powder pattern [88, 89]. Besides peak broadening, peaks may also become asymmetrical and/or shift with respect to their unmilled counterpart due to plastic deformation. All these effects on diffraction profile of a ball-milled sample (cold-worked) are related to several microstructural parameters like: change in lattice parameter, residual stress, density of stacking, twin/growth faults, coherently diffracting domain size (particle size), r.m.s. lattice strain, dislocation density, and stacking fault energy.

2.2. Preparing Tailor-Made Nanocrystals. All the microstructural parameters can be estimated quantitatively by analyzing the XRD patterns of ball-milled samples employing Rietveld's structure refinement method. The Rietveld's method of analysis based on structural and microstructural refinement is the best approach to characterize microstructure of ball-milled samples containing lattice imperfections of different kind. As the microstructural parameters are directly related to several physical properties of a material, 


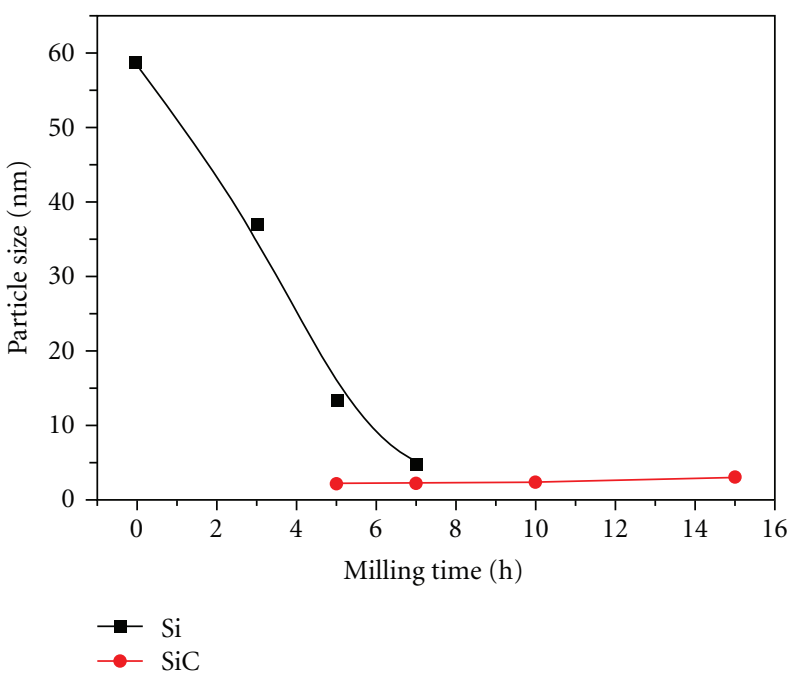

(a)

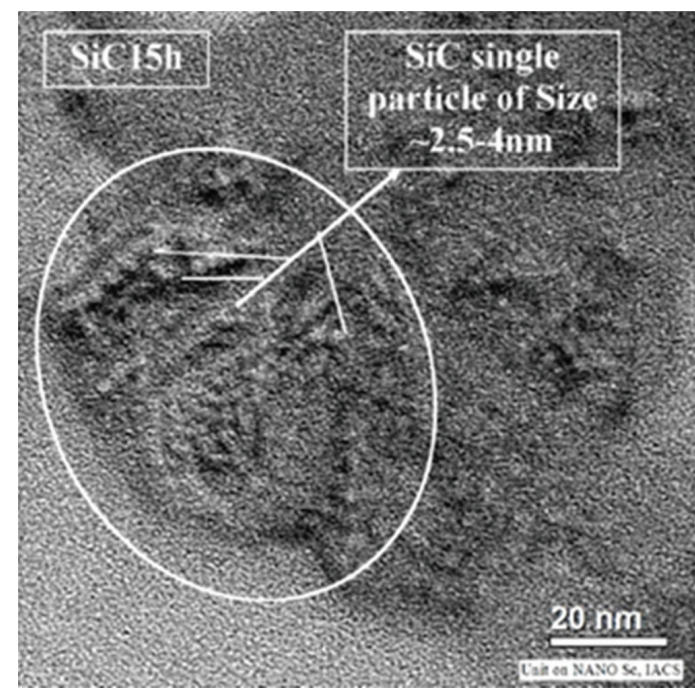

(b)

FIgure 1: (a) Particle size of Si and SiC phases in unmilled and ball-milled mixture of Si and graphite (1:1 mol) with increasing milling time. (b) HRTEM micrograph of $\mathrm{SiC}$ phase after $15 \mathrm{~h}$ ball-milling.

a control over the microstructure leads one to prepare "tailor made" materials having desirable properties.

Ghosh and Pradhan [90] mechanically alloyed the elemental Si and C (Graphite) powders under Ar using a highenergy planetary ball mill at room temperature for different durations and then investigated the alloying mechanism during MA by successive modifications of X-ray powder diffraction pattern of ball-milled samples. The microstructural characterisation of ball-milled samples, done by the authors, by Rietveld's analysis, reveals that at the early stage of milling, graphite layers are distributed on the Si nanograin boundaries as very thin layers and full formation of nanocrystalline $\mathrm{SiC}$ phase is observed after $15 \mathrm{~h}$ of milling (Figure 1).

\section{Conclusion: Goal Is yet to Be Reached}

As silicon-based microelectronic devices are approaching the physical limits, the constant push to develop better and faster devices and higher computing power has spurred the development of substituting materials. In this regard, silicon carbide is a good candidate in high-power, hightemperature, and high-frequency applications.

Extensive studies on silicon carbide nanostructures such as nanocrystals, nanowires and nanotubes, and nanosized films began in the mid-1990s, and we have aimed, in this paper, at reviewing the role of $\mathrm{SiC}$ nanostructures in the field of photo science, in a broad sense, already published in the past years. However, it should be noted that researches on silicon carbide nanostructures are still in the beginning stage. Contrary to nanostructured silicon, $\mathrm{SiC}$ nanostructures have been subjected to a much smaller amount of theoretical and experimental works devoted to the understanding of the light-induced electronic processes. Although clear quantum confinement of 3C-SiC has been observed [91], the specific defect or surface states responsible for the observed luminescence have not been unequivocally identified. Much more experimental and theoretical work is needed. Finally, there have only been a few theoretical studies on $\mathrm{SiC}$ nanostructures. A better understanding of the various properties of these nanostructures is needed in order to realize their full potentials.

\section{References}

[1] O. Madelung, Semiconductors: Data Handbook, Springer, Berlin, Germany, 3rd edition, 2004.

[2] S. Charpentier, A. Kassiba, A. Bulou, M. Monthioux, and M. Cauchetier, "Effects of excess carbon and vibrational properties in ultrafine SiC powders," The European Physical Journal Applied Physics, vol. 8, no. 2, pp. 111-121, 1999.

[3] A. Kassiba, M. Makowska-Janusik, J. Bouclé, J. F. Bardeau, A. Bulou, and N. Herlin-Boime, "Photoluminescence features on the Raman spectra of quasistoichiometric SiC nanoparticles: experimental and numerical simulations," Physical Review B, vol. 66, no. 15, Article ID 155317, 2002.

[4] M. Makowska-Janusik, A. Kassiba, J. Bouclé, J. F. Bardeau, S. Kodjikian, and A. Désert, "Vibrational density of states in silicon carbide nanoparticles: experiments and numerical simulations," Journal of Physics Condensed Matter, vol. 17, no. 33, pp. 5101-5110, 2005.

[5] S. Santavirta, M. Takagi, L. Nordsletten, A. Anttila, R. Lappalainen, and Y. T. Konttinen, "Biocompatibility of silicon carbide in colony formation test in vitro. A promising new ceramic THR implant coating material," Archives of Orthopaedic and Trauma Surgery, vol. 118, no. 1-2, pp. 89-91, 1998.

[6] J. Botsoa, V. Lysenko, A. Géloën, O. Marty, J. M. Bluet, and G. Guillot, "Application of 3C-SiC quantum dots for living cell imaging," Applied Physics Letters, vol. 92, no. 17, Article ID 173902, 2008.

[7] M. Bruchez Jr., M. Moronne, P. Gin, S. Weiss, and A. P. Alivisatos, "Semiconductor nanocrystals as fluorescent biological labels,” Science, vol. 281, no. 5385, pp. 2013-2016, 1998. 
[8] J. M. Klostranec and W. C. W. Chan, "Quantum dots in biological and biomedical research: recent progress and present challenges," Advanced Materials, vol. 18, no. 15, pp. 1953-1964, 2006.

[9] J. C. Vial, A. Bsiesy, F. Gaspard et al., "Mechanisms of visiblelight emission from electro-oxidized porous silicon," Physical Review B, vol. 45, no. 24, pp. 14171-14176, 1992.

[10] U. Resch-Genger, M. Grabolle, S. Cavaliere-Jaricot, R. Nitschke, and T. Nann, "Quantum dots versus organic dyes as fluorescent labels," Nature Methods, vol. 5, no. 9, pp. 763-775, 2008.

[11] M. Nirmal and L. Brus, "Luminescence photophysics in semiconductor nanocrystals," Accounts of Chemical Research, vol. 32, no. 5, pp. 407-414, 1999.

[12] T. Pellegrino, S. Kudera, T. Liedl, A. M. Javier, L. Manna, and W. J. Parak, "On the development of colloidal nanoparticles towards multifunctional structures and their possible use for biological applications," Small, vol. 1, no. 1, pp. 48-63, 2005.

[13] X. Michalet, F. F. Pinaud, L. A. Bentolila et al., "Quantum dots for live cells, in vivo imaging, and diagnostics," Science, vol. 307, no. 5709, pp. 538-544, 2005.

[14] D. A. Giljohann and C. A. Mirkin, "Drivers of biodiagnostic development," Nature, vol. 462, no. 7272, pp. 461-464, 2009.

[15] M. Stutzmann, J. A. Garrido, M. Eickhoff, and M. S. Brandt, "Direct biofunctionalization of semiconductors: a survey," Physica Status Solidi (A), vol. 203, no. 14, pp. 3424-3437, 2006.

[16] J. Fan and P. K. Chu, "Group IV nanoparticles: synthesis, properties, and biological applications," Small, vol. 6, no. 19, pp. 2080-2098, 2010.

[17] A. H. Yuwono, J. Xue, J. Wang et al., "Transparent nanohybrids of nanocrystalline $\mathrm{TiO} 2$ in PMMA with unique nonlinear optical behavior," Journal of Materials Chemistry, vol. 13, no. 6, pp. 1475-1479, 2003.

[18] K. R. Choudhury, J. G. Winiarz, M. Samoc, and P. N. Prasad, "Charge carrier mobility in an organic-inorganic hybrid nanocomposite," Applied Physics Letters, vol. 82, no. 3, pp. 406-408, 2003.

[19] M. M. Erwin, A. V. Kadavanich, J. McBride, T. Kippeny, S. Pennycook, and S. J. Rosenthal, "Material characterization of a nanocrystal based photovoltaic device," European Physical Journal D, vol. 8, no. 3, pp. 275-277, 2000.

[20] J. Bouclé, A. Kassiba, M. Makowska-Janusik et al., "Linear electro-optical behavior of hybrid nanocomposites based on silicon carbide nanocrystals and polymer matrices," Physical Review B, vol. 74, no. 20, Article ID 205417, 2006.

[21] L. T. Canham, "Silicon quantum wire array fabrication by electrochemical and chemical dissolution of wafers," Applied Physics Letters, vol. 57, no. 10, pp. 1046-1048, 1990.

[22] G. Voskerician, M. S. Shive, R. S. Shawgo et al., "Biocompatibility and biofouling of MEMS drug delivery devices," Biomaterials, vol. 24, no. 11, pp. 1959-1967, 2003.

[23] J. H. Warner, A. Hoshino, K. Yamamoto, and R. D. Tilley, "Water-soluble photoluminescent silicon quantum dots," Angewandte Chemie, vol. 44, no. 29, pp. 4550-4554, 2005.

[24] C. I. Harris, S. Savage, A. Konstantinov, M. Bakowski, and P. Ericsson, "Progress towards SiC products," Applied Surface Science, vol. 184, no. 1-4, pp. 393-398, 2001.

[25] P. Masri, "Silicon carbide and silicon carbide-based structures: the physics of epitaxy," Surface Science Reports, vol. 48, no. $1-4$, pp. 1-51, 2002.

[26] C. Coletti, M. J. Jaroszeski, A. Pallaoro, A. M. Hoff, S. Iannotta, and S. E. Saddow, "Biocompatibility and wettability of crystalline SiC and Si surfaces," in Proceedings of the 29th Annual International Conference of IEEE-EMBS, Engineering in Medicine and Biology Society (EMBC '07), pp. 5849-5852, August 2007.

[27] X. L. Wu, J. Y. Fan, T. Qiu, X. Yang, G. G. Siu, and P. K. Chu, "Experimental evidence for the quantum confinement effect in 3C-SiC nanocrystallites," Physical Review Letters, vol. 94, no. 2, Article ID 026102, 2005.

[28] A. Kassiba, M. Tabellout, S. Charpentier, N. Herlin, and J. R. Emery, "Conduction and dielectric behaviour of $\mathrm{SiC}$ nano-sized materials," Solid State Communications, vol. 115, no. 7, pp. 389-393, 2000.

[29] M. Tabellout, A. Kassiba, S. Tkaczyk, L. Laskowski, and J. Swiatek, "Dielectric and EPR investigations of stoichiometry and interface effects in silicon carbide nanoparticles," Journal of Physics Condensed Matter, vol. 18, no. 4, pp. 1143-1155, 2006.

[30] A. Kassiba, Nanostructured Silicon Based Powders and Composites, Francis \& Taylor (GB), 2002.

[31] V. Lehmann and U. Gösele, "Porous silicon formation: a quantum wire effect," Applied Physics Letters, vol. 58, no. 8, pp. 856-858, 1991.

[32] J. L. Heinrich, C. L. Curtis, G. M. Credo, K. L. Kavanagh, and M. J. Sailor, "Luminescent colloidal silicon suspensions from porous silicon," Science, vol. 255, no. 5040, pp. 66-68, 1992.

[33] L. E. Brus, P. F. Szajowski, W. L. Wilson, T. D. Harris, S. Schuppler, and P. H. Citrin, "Electronic spectroscopy and photophysics of Si nanocrystals: relationship to bulk c-Si and porous Si," Journal of the American Chemical Society, vol. 117, no. 10, pp. 2915-2922, 1995.

[34] G. Belomoin, J. Therrien, A. Smith et al., "Observation of a magic discrete family of ultrabright Si nanoparticles," Applied Physics Letters, vol. 80, no. 5, pp. 841-843, 2002.

[35] G. Ledoux, J. Gong, F. Huisken, O. Guillois, and C. Reynaud, "Photoluminescence of size-separated silicon nanocrystals: confirmation of quantum confinement," Applied Physics Letters, vol. 80, no. 25, pp. 4834-4836, 2002.

[36] U. Starke, "Atomic structure of hexagonal SiC surfaces," Physica Status Solidi (B), vol. 202, no. 1, pp. 475-499, 1997.

[37] P. Soukiassian, "Cubic silicon carbide surface reconstructions and Si (C) nanostructures at the atomic scale," Materials Science and Engineering B, vol. 96, no. 2, pp. 115-131, 2002.

[38] V. Derycke, P. G. Soukiassian, F. Amy et al., "Nanochemistry at the atomic scale revealed in hydrogen-induced semiconductor surface metallization," Nature Materials, vol. 2, no. 4, pp. 253-258, 2003.

[39] L. J. Brillson, S. Tumakha, R. S. Okojie, M. Zhang, and P. Pirouz, "Electron-excited luminescence of $\mathrm{SiC}$ surfaces and interfaces," Journal of Physics Condensed Matter, vol. 16, no. 17, pp. S1733-S1754, 2004.

[40] V. Petrova-Koch, O. Sreseli, G. Polisski, D. Kovalev, T. Muschik, and F. Koch, "Luminescence enhancement by electrochemical etching of SiC(6H)," Thin Solid Films, vol. 255, no. 1-2, pp. 107-110, 1995.

[41] D. H. Feng, Z. Z. Xu, T. Q. Jia, X. X. Li, and S. Q. Gong, "Quantum size effects on exciton states in indirect-gap quantum dots," Physical Review B, vol. 68, no. 3, Article ID 035334, 2003.

[42] F. A. Reboredo, L. Pizzagalli, and G. Galli, "Computational engineering of the stability and optical gaps of $\mathrm{SiC}$ quantum dots," Nano Letters, vol. 4, no. 5, pp. 801-804, 2004.

[43] R. Rurali, "Electronic and structural properties of silicon carbide nanowires," Physical Review B, vol. 71, no. 20, Article ID 205405, 2005.

[44] R. P. Devaty and W. J. Choyke, "Optical characterization of silicon carbide polytypes," Physica Status Solidi (A), vol. 162, no. 1, pp. 5-38, 1997. 
[45] A. G. Cullis, L. T. Canham, and P. D. J. Calcott, "The structural and luminescence properties of porous silicon," Journal of Applied Physics, vol. 82, no. 3, pp. 909-965, 1997.

[46] A. L. Efros and A. L. Efros, "Interband absorption of light in a semiconductor sphere," Soviet Physics, vol. 16, no. 7, pp. 772-775, 1982.

[47] L. E. Brus, "A simple model for the ionization potential, electron affinity, and aqueous redox potentials of small semiconductor crystallites," The Journal of Chemical Physics, vol. 79, no. 11, pp. 5566-5571, 1983.

[48] H. Morkoç, S. Strite, G. B. Gao, M. E. Lin, B. Sverdlov, and M. Burns, "Large-band-gap SiC, III-V nitride, and II-VI ZnSe-based semiconductor device technologies," Journal of Applied Physics, vol. 76, no. 3, pp. 1363-1398, 1994.

[49] G. E. Carter, J. B. Casady, and J. Bonds, "Preliminary investigation of SiC on Silicon for biomedical applications," Materials Science Forum, vol. 338, pp. 1149-1152, 2000.

[50] W. C. W. Chan and S. Nie, "Quantum dot bioconjugates for ultrasensitive nonisotopic detection," Science, vol. 281, no. 5385, pp. 2016-2018, 1998.

[51] H. Dai, E. W. Wong, Y. Z. Lu, S. Fan, and C. M. Lieber, "Synthesis and characterization of carbide nanorods," Nature, vol. 375, no. 6534, pp. 769-772, 1995.

[52] X. H. Sun, C. P. Li, W. K. Wong et al., "Formation of silicon carbide nanotubes and nanowires via reaction of silicon (from disproportionation of silicon monoxide) with carbon nanotubes," Journal of the American Chemical Society, vol. 124, no. 48, pp. 14464-14471, 2002.

[53] D. Appell, "Wired for success," Nature, vol. 419, no. 6907, pp. 553-555, 2002.

[54] Z. Pan, H. L. Lai, F. C. K. Au et al., "Oriented silicon carbide nanowires: synthesis and field emission properties," Advanced Materials, vol. 12, no. 16, pp. 1186-1190, 2000.

[55] Z. S. Wu, S. Z. Deng, N. S. Xu, J. Chen, J. Zhou, and J. Chen, "Needle-shaped silicon carbide nanowires: synthesis and field electron emission properties," Applied Physics Letters, vol. 80, no. 20, pp. 3829-3831, 2002.

[56] Y. Zhang, T. Ichihashi, E. Landree, F. Nihey, and S. Iijima, "Heterostructures of single-walled carbon nanotubes and carbide nanorods," Science, vol. 285, no. 5434, pp. 1719-1722, 1999.

[57] M. B. Yu, Rusli, S. F. Yoon et al., "Hydrogenated nanocrystalline silicon carbide films synthesized by ECR-CVD and its intense visible photoluminescence at room temperature," Thin Solid Films, vol. 377-378, pp. 177-181, 2000.

[58] G. Cicero, A. Catellani, and G. Galli, "Atomic control of water interaction with biocompatible surfaces: the case of $\mathrm{SiC}(001)$," Physical Review Letters, vol. 93, no. 1, Article ID 016102, 2004.

[59] R. E. Bailey, A. M. Smith, and S. Nie, "Quantum dots in biology and medicine," Physica E, vol. 25, no. 1, pp. 1-12, 2004.

[60] E. W. Wong, P. E. Sheehan, and C. M. Lieber, "Nanobeam mechanics: elasticity, strength, and toughness of nanorods and nanotubes," Science, vol. 277, no. 5334, pp. 1971-1975, 1997.

[61] J. J. Niu and J. N. Wang, "Synthesis of macroscopic SiC nanowires at the gram level and their electrochemical activity with Pt loadings," Acta Materialia, vol. 57, no. 10, pp. 3084-3090, 2009.

[62] J. J. Biernacki and G. P. Wotzak, "Stoichiometry of the $\mathrm{C}+\mathrm{SiO}_{2}$ reaction," Journal of the American Ceramic Society, vol. 72, no. 1, pp. 122-129, 1989.

[63] Y. Kamlag, A. Goossens, I. Colbeck, and J. Schoonman, "Laser CVD of cubic SiC nanocrystals," Applied Surface Science, vol. 184, no. 1-4, pp. 118-122, 2001.
[64] G. Shen, D. Chen, K. Tang, Y. Qian, and S. Zhang, "Silicon carbide hollow nanospheres, nanowires and coaxial nanowires," Chemical Physics Letters, vol. 375, no. 1-2, pp. 177-184, 2003.

[65] S. Larpkiattaworn, P. Ngernchuklin, W. Khongwong, N. Pankurddee, and S. Wada, "The influence of reaction parameters on the free $\mathrm{Si}$ and $\mathrm{C}$ contents in the synthesis of nano-sized SiC," Ceramics International, vol. 32, no. 8, pp. 899-904, 2006.

[66] G. W. Ho, A. S. W. Wong, D. J. Kang, and M. E. Welland, "Three-dimensional crystalline SiC nanowire flowers," Nanotechnology, vol. 15, no. 8, pp. 996-999, 2004.

[67] A. Markwitz, S. Johnson, M. Rudolphi, H. Baumann, and A. Mücklich, "Formation of SiC-surface nanocrystals by ion implantation and electron beam rapid thermal annealing," Applied Physics Letters, vol. 86, no. 1, Article ID 013108, 2005.

[68] S. Milita, M. De Santis, D. Jones, A. Parisini, and V. Palermo, "Real time investigation of the growth of silicon carbide nanocrystals on $\mathrm{Si}\left(\begin{array}{lll}1 & 0 & 0\end{array}\right)$ using synchrotron X-ray diffraction," Applied Surface Science, vol. 254, no. 7, pp. 2162-2167, 2008.

[69] P. Majewski, N. R. Choudhury, D. Spori, E. Wohlfahrt, and M. Wohlschloegel, "Synthesis and characterisation of star polymer/silicon carbide nanocomposites," Materials Science and Engineering A, vol. 434, no. 1-2, pp. 360-364, 2006.

[70] J. Bouclé, A. Kassiba, J. Emery et al., "Local electrooptic effect of the SiC large-sized nanocrystallites incorporated in polymer matrices," Physics Letters Section A, vol. 302, no. 4, pp. 196-202, 2002.

[71] V. A. Izhevskyi, L. A. Genova, J. C. Bressiani, and A. H. A. Bressiani, "Liquid-phase sintering of SiC-based ceramics," Key Engineering Materials, vol. 189—191, pp. 173-180, 2001.

[72] V. A. Izhevskyi, L. A. Genova, A. H. A. Bressiani, and J. C. Bressiani, "Liquid phase sintered SiC. Processing and transformation controlled microstructure tailoring," Materials Research, vol. 3, no. 4, pp. 131-138, 2000.

[73] J. H. Kang, H. M. Cha, J. H. Lee, Y. G. Jung, H. S. Lee, and V. K. Srivastava, "Synthesis and characterization of non-oxide ceramic coatings on graphite substrates by solid-vapor reaction process," Progress in Organic Coatings, vol. 61, no. 2-4, pp. 291-299, 2008.

[74] Y. H. Yun, S. C. Choi, J. C. Chang, and J. C. Kim, “The conversion mechanism of $\mathrm{SiC}$ conversion layers on graphite substrates by CVR (Chemical Vapor Reaction)," Journal of Ceramic Processing Research, vol. 2, pp. 129-133, 2001.

[75] M. Sherif El-Eskandarany, K. Sumiyama, and K. Suzuki, "Mechanical solid state reaction for synthesis of $\beta$-SiC powders," Journal of Materials Research, vol. 10, no. 3, pp. 659-667, 1995.

[76] T. Tanaka, K. N. Ishihara, and P. H. Shingu, "Formation of metastable phases of Ni-C," Metallurgical Transactions A, vol. 23, no. 9, pp. 2431-2435, 1992.

[77] A. Calka, "Mechanical alloying: technology and properties of prepared materials," Key Engineering Materials, vol. 81-83, pp. 17-24, 1993.

[78] C. Suryanarayana, "Mechanical alloying and milling," Progress in Materials Science, vol. 46, no. 1-2, pp. 1-184, 2001.

[79] M. H. Enayati, M. Seyed-Salehi, and A. Sonboli, "Development of Fe3C, SiC and Al4C3 compounds during mechanical alloying," Journal of Materials Science, vol. 42, no. 15, pp. 5911-5914, 2007.

[80] B. H. Lohse, A. Calka, and D. Wexler, "Effect of starting composition on the synthesis of nanocrystalline TiC during milling of titanium and carbon," Journal of Alloys and Compounds, vol. 394, no. 1-2, pp. 148-151, 2005.

[81] M. Sherif El-Eskandarany, "Structure and properties of nanocrystalline TiC full-density bulk alloy consolidated 
from mechanically reacted powders," Journal of Alloys and Compounds, vol. 305, no. 1-2, pp. 225-238, 2000.

[82] B. Ghosh and S. K. Pradhan, "Microstructure characterization of nanocrystalline $\mathrm{Fe} 3 \mathrm{C}$ synthesized by high-energy ball milling," Journal of Alloys and Compounds, vol. 477, no. 1-2, pp. 127-132, 2009.

[83] B. Ghosh, H. Dutta, and S. K. Pradhan, "Microstructure characterization of nanocrystalline $\mathrm{Ni3C}$ synthesized by high-energy ball milling," Journal of Alloys and Compounds, vol. 479, no. 1-2, pp. 193-200, 2009.

[84] C. J. Lu and Z. Q. Li, "Structural evolution of the Ti-Si-C system during mechanical alloying," Journal of Alloys and Compounds, vol. 395, no. 1-2, pp. 88-92, 2005.

[85] H. Abderrazak and M. Abdellaoui, "Synthesis and characterization of nanostructured silicon carbide," Materials Letters, vol. 62, no. 23, pp. 3839-3841, 2008.

[86] X. Y. Yang, Z. W. Huang, Y. K. Wu, and H. Q. Ye, "HREM observations of the synthesized proces of nano-sized SiC by ball milling of Si and C mixed powders," Materials Science and Engineering A, vol. 300, no. 1-2, pp. 278-283, 2001.

[87] J. Rodríguez-Carvajal, "Recent advances in magnetic structure determination by neutron powder diffraction," Physica B, vol. 192, no. 1-2, pp. 55-69, 1993.

[88] B. E. Warren, X-Ray Diffraction, Wesley, Reading, Mass, USA, 1969.

[89] C. N. G. Wagner, J. B. Cohen, and J. E. Hilliard, Eds., Local Atomic Arrangements Studied by X-Ray Diffraction, Gordon and Breach, New York, NY, USA, 1966.

[90] B. Ghosh and S. K. Pradhan, "Microstructural characterization of nanocrystalline $\mathrm{SiC}$ synthesized by high-energy ball-milling," Journal of Alloys and Compounds, vol. 486, no. 1-2, pp. 480-485, 2009.

[91] G. Wei, W. Qin, R. Kim et al., "Quantum confinement effect and field emission characteristics of ultrathin 3C-SiC nanobelts," Chemical Physics Letters, vol. 461, no. 4-6, pp. 242-245, 2008. 


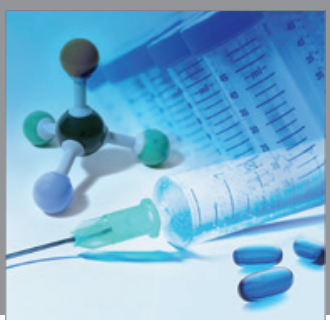

International Journal of

Medicinal Chemistry

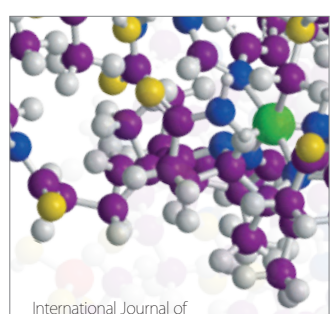

Carbohydrate Chemistry

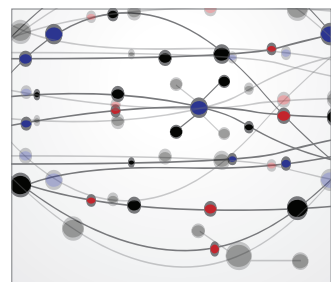

The Scientific World Journal
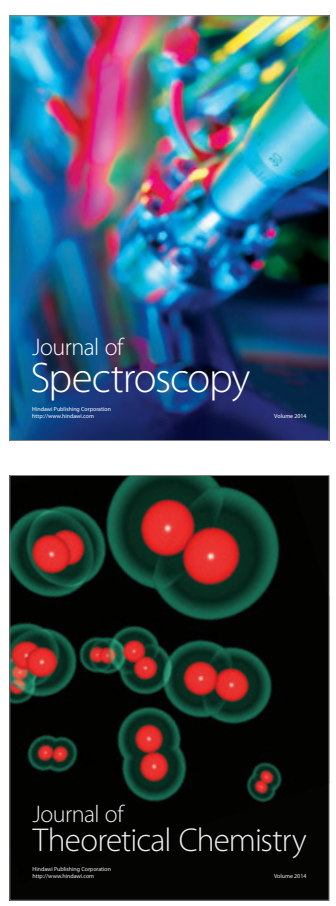
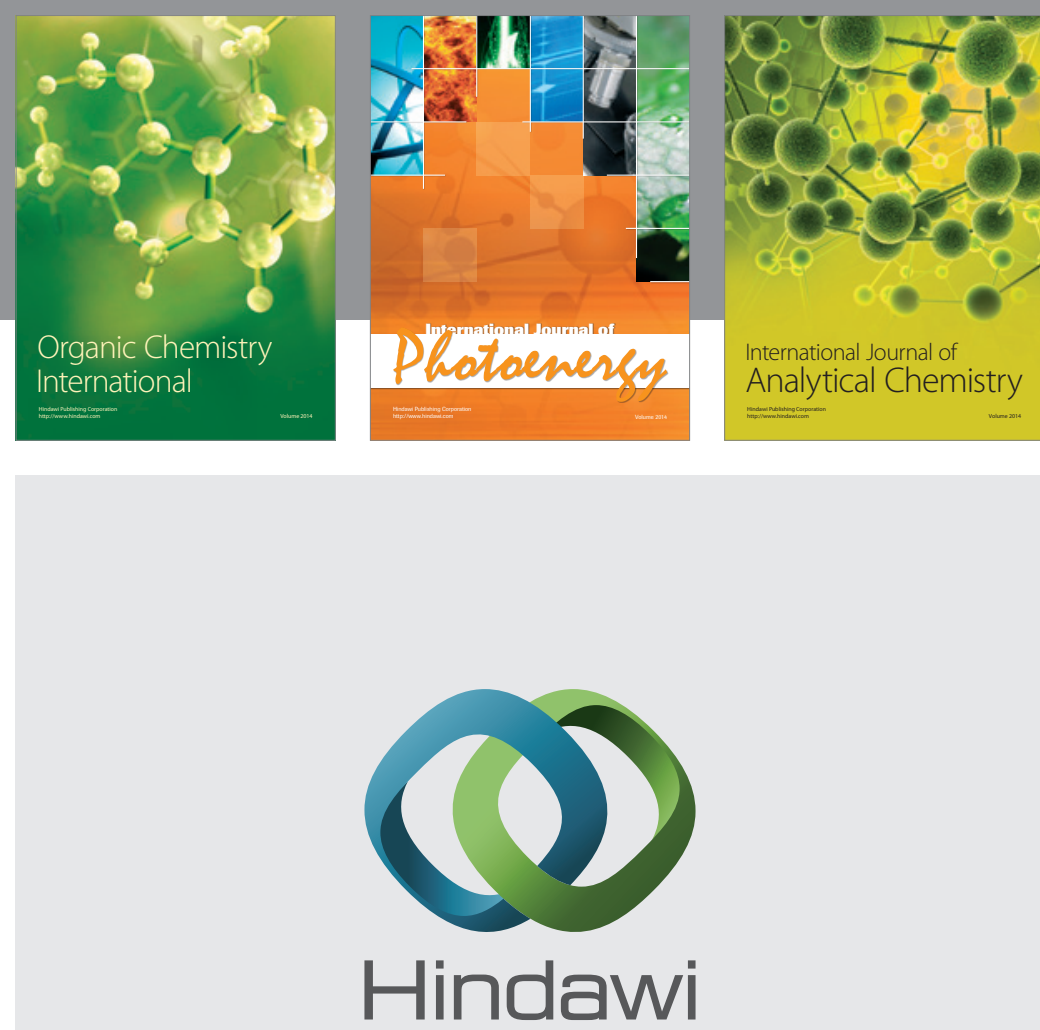

Submit your manuscripts at

http://www.hindawi.com
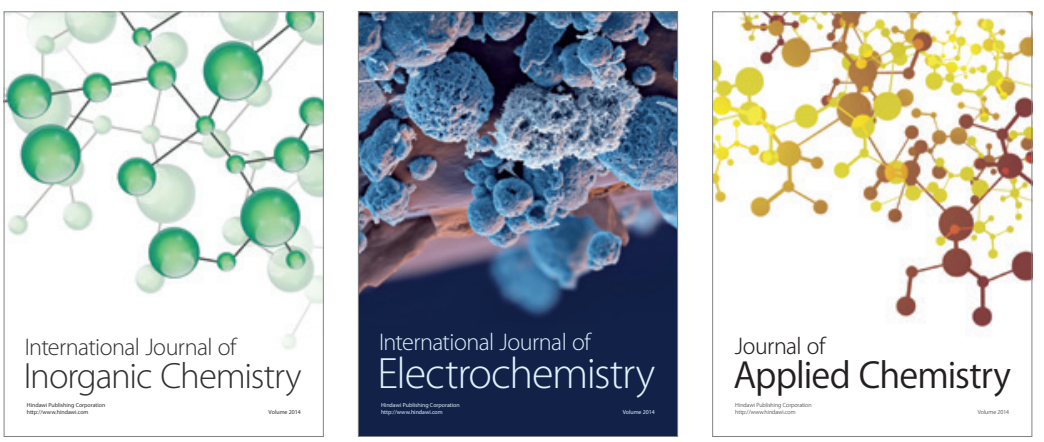

Journal of

Applied Chemistry
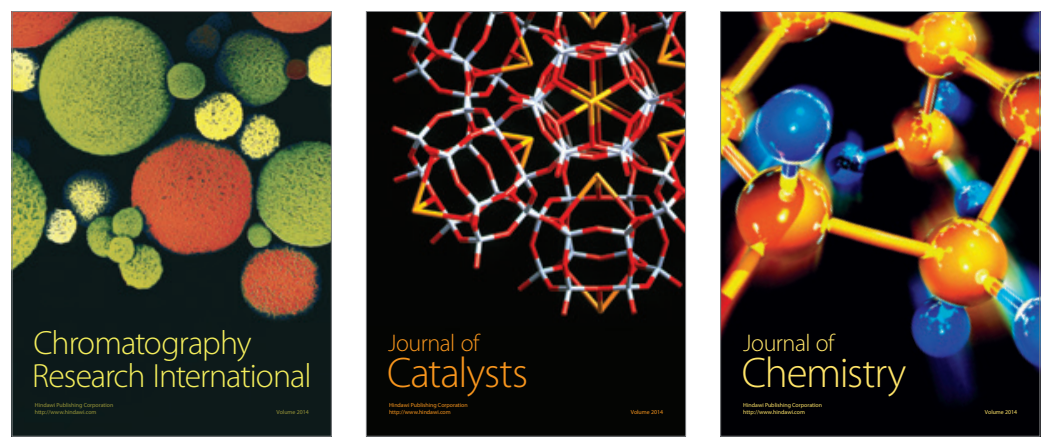
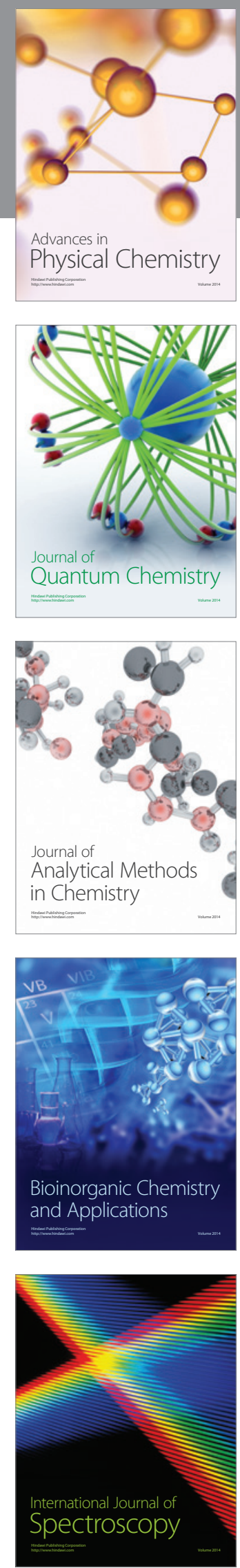